\title{
Factors associated with smoking cessation and relapse in the Japanese smoking cessation treatment program: A prospective cohort study based on financial support in Suita City, Japan
}

\author{
Meng Li', Reiko Okamoto', Fumie Shirai ${ }^{2}$
}

\begin{abstract}
INTRODUCTION The purpose of this study is to clarify the effect of providing financial support and factors associated with smoking cessation and relapse in the Japanese smoking cessation treatment (SCT) program based on financial support.

METHODS A prospective cohort study was conducted at the smoking cessation outpatients of hospitals or clinics in Suita City, Japan from May 2017 to September 2018. In all, 153 participants were recruited and received standardized treatment based on the SCT program. Participants were required to answer four questionnaires and register for the financial support program. Chi-squared test, Fisher's exact test, non-paired t-test and log-binomial regression analysis were used to analyze the data.

RESULTS Of the 153 participants, 140 participants completed a 12-week treatment and the completion rate was $91.5 \%$. There were no factors significantly associated with smoking cessation and relapse $(\mathrm{p}<0.05)$. However, male, cigarettes smoked per day, having present diseases, having previous abstinence, living with family, cohabitation with smokers, desire to smoke at the start of treatment, self-efficacy at the start of treatment, desire to smoke at 4 weeks and self-efficacy at 4 weeks showed statistically significant odds ratio for success of smoking cessation. Similarly at 12 weeks, male, age at smoking initiation, cigarettes smoked per day, having previous abstinence, living with family, cohabitation with smokers, desire to smoke, self-efficacy and depression disorders showed statistically significant odds ratio for smoking relapse. In addition, the rate of abstainers using varenicline was $68.60 \%$, which was higher than abstainers using nicotine patch $(55.60 \%)$ and the relapse rate of participants using nicotine patch was $100.00 \%$, significantly higher than for relapsers using varenicline $(45.80 \%)$.

CONCLUSIONS Further study is expected to clarify the effect of providing financial support and the factors associated with smoking cessation and relapse in the SCT program based on financial support.
\end{abstract}

\section{INTRODUCTION}

Tobacco use is a significant public health concern worldwide and one of the major causes of death and disability in both developed and developing countries. According to the 2017 World Health Organization
(WHO) report $^{1}$, tobacco use is currently responsible for the death of about 7 million people worldwide each year, including 600 thousand deaths due to passive smoking. To reduce health problems due to smoking or passive smoking, WHO has enacted the 
Framework Convention on Tobacco Control (FCTC) in the World Health Assembly, 21 May 2003, and the convention gives specific recommendations for different tobacco control strategies such as developing comprehensive smoking cessation guidelines and introducing warning labels on cigarette packages ${ }^{2}$. In these strategies, one approach to promote tobacco control is to take effective measures to promote smoking cessation and offer an adequate treatment program for tobacco dependence.

In Japan, tobacco use has become the leading preventable cause of mortality and morbidity, resulting in about 129 thousand deaths ${ }^{3}$. In light of this troubling fact, the Japanese medical insurance system has covered the smoking cessation treatment (SCT) program for nicotine dependence since 2006. Until March 2018, more than 16400 facilities have established smoking cessation outpatients or clinics, and the treatment population has been expanded to young people under 35 years of age, regardless of the Brinkman Index. With the development of smoking cessation treatment in Japan, a large number of studies have investigated factors associated with smoking cessation and relapse in the SCT program. In addition, to improve the effects of treatment, Arakawa Ward, Tokyo was first to provide financial support for the SCT program since 2007, and thereafter a similar support program has been extended to other wards and cities. However, the effects of providing financial support and factors associated with smoking cessation and relapse in the SCT program based on financial support have not been reported. Therefore, the purpose of this study is to clarify the effects of providing financial support and factors associated with smoking cessation and relapse in the SCT program based on financial support.

\section{METHODS}

\section{Design}

A prospective cohort study was conducted at the smoking cessation outpatients of several hospitals or smoking cessation clinics in Suita City, Japan from May 2017 to September 2018. In all, 153 participants were recruited and received treatment based on the 6th standardized guideline ${ }^{4}$ of the SCT program. Meanwhile, participants were required to answer four questionnaires at the start of treatment, at 4 weeks, at 12 weeks, and at 1 year, and register for the financial support program (cost: 10000 yen, about US\$92.87) within one month before or after the start of treatment. In order to earn the financial support after the treatment, three conditions must be met, as follows:

1. Applicants must complete a 12 -week treatment program.

2. Applicants are limited to 100 people if over 100 people complete this program, meanwhile over 100 people applied for the financial support.

3. Applicants must submit relevant materials (financial support application form, receipt, medical expense statement, etc.) within about one month after the treatment.

The applications for financial support and the responses of four questionnaires were completed at the reception counter of the Health Center of Suita City or by mail. This study was approved by the Ethical Committee of Observation Research at the Osaka University Hospital (Approval No: 18362), and the division of roles was implemented based on a joint research contract between Suita City and Osaka University.

\section{The Japanese SCT program}

The Japanese SCT program has been described in previous studies ${ }^{5,6}$. Briefly, the SCT program consists of a total of five sessions: first session and then followup sessions at $2,4,8$ and 12 weeks after the first session. At each session, the current smoking behavior is confirmed by exhaled carbon monoxide (CO) concentration and the smoker's self-reported smoking status. Meanwhile, patients receive medication treatment consisting of varenicline (standard use: 12 weeks) or nicotine patches (standard use: 8 weeks), and behavioral counselling from physicians and nurses.

\section{Data collection}

Data collection involves four questionnaires at the start of treatment, at 4 weeks, at 12 weeks, and at 1 year. The four questionnaires were developed based on previous studies ${ }^{5,6}$ and specialists' opinions from Osaka University and the Health Center of Suita City. The first questionnaire at the start of treatment includes information on age, gender, age at smoking initiation, cigarettes smoked per day, previous abstinence, selfefficacy, cohabiter, cohabitation with smokers, passive 
smoking, having present diseases, strength of desire to smoke, and a CES-D score (Center for Epidemiologic Studies Depression Scale). The second questionnaire at 4 weeks includes information on smoking status, self-efficacy, strength of desire to smoke, satisfaction with smoking cessation treatment, and received instructions during the period of SCT. The third questionnaire at 12 weeks includes information on smoking status at 8 weeks and 12 weeks, self-efficacy, strength of desire to smoke, satisfaction with smoking cessation treatment, received instructions during the period of SCT, CES-D score, thoughts and feelings for financial support (free description). The fourth questionnaire at 1 year includes information on smoking status at 1 year, self-efficacy, strength of desire to smoke, received instructions during the period of SCT, CES-D score, thoughts and feelings for challenge to quit smoking (free description).

\section{Strength of desire to smoke}

Strength of desire to smoke (craving) is evaluated by grades ( 0 : none; 1 : slight; 2 : moderate; 3 : strong) based on the combination of two questions: 'How many times did you want to smoke in the past two weeks?' (with responses, 0: Not at all; 1: Several times a week; 2: Several times a day; 3: Many times a day), and 'How strongly did you want to smoke in the past two weeks?' (with responses, 0: Not at all; 1: Several times a week; 2: Several times a day; 3: Many times a day $)^{7}$.

\section{CES-D scale}

The CES-D scale is designed to measure depressive symptomatology in the general population, including 20 short self-report items. The component mainly consists of depressed mood, feelings of guilt and worthlessness, feelings of helplessness and hopelessness, psychomotor retardation, loss of appetite, and sleep disturbance. The responses of each item are weighted by frequency of occurrence of the symptom scoring from zero to three during the past week, and the possible range of CES-D scored from zero to sixty. The higher scores indicate more symptoms and over 16 points are diagnosed as being in a mood disorder group ${ }^{7}$.

\section{Self-efficacy scale}

Self-efficacy in the smoking cessation treatment is defined as the confidence a person had in his/her ability to quit smoking and prevent relapse after a quit attempt. In the past, various questionnaires have been used to measure self-efficacy with regard to smoking cessation. A recent meta-analysis study reported that the effect size of self-efficacy with single-item measures was stronger than multi-item measures. Therefore, the self-efficacy scale with a singleitem 0-100 rating is used to evaluated participants' confidence for smoking cessation in this study. The self-efficacy to quit smoking is asked in four questionnaires: 'How much, as a per cent, confidence do you have to quit smoking?', with $0 \%$ corresponding to 'I don't have confidence at all to quit smoking' and $100 \%$ corresponding to 'I absolutely have confidence to quit smoking ${ }^{8,9}$.

\section{Definition of smoking status}

In this study, success of smoking cessation (abstainer) is defined as at least previous 4 weeks of smoking abstinence at the end of the SCT program (12 weeks) from the third self-reported questionnaire. Maintained cessation (non-relapser) is defined as smoking abstinence at 1 year from the fourth selfreported questionnaire. Participants who do not reply to the questionnaire or answer continuous smoking in the questionnaires are defined as failure of smoking cessation (non-abstainer) at 12 weeks and smoking relapse (relapser) at 1 year.

\section{Statistical analysis}

Statistical analysis was divided into three stages. First, gender, age at smoking initiation, cigarettes smoked per day, previous abstinence, cohabiter, cohabitation with smokers, smokers at workplace or familiar places, having present diseases, strength of desire to smoke at the start of treatment, self-efficacy at the start of treatment, CES-D score at the start of treatment were presented by frequency distribution and percentage; while age, age at smoking initiation, cigarettes smoked per day, self-efficacy and CES-D score were also presented as mean and standard deviation (SD). Second, chi-squared test and nonpaired t-test were used to examine the association between success of smoking cessation and age, gender, age at smoking initiation, cigarettes smoked per day, previous abstinence, cohabiter, cohabitation with smokers, smokers at workplace or familiar 
places, having present diseases, strength of desire to smoke at the start of treatment, self-efficacy at the start of treatment, CES-D score at the start of treatment, self-efficacy at 4 weeks, and strength of desire to smoke at 4 weeks. Subsequently, logbinomial regression analysis was used to examine factors associated with success of smoking cessation at 12 weeks. Similarly, chi-squared test and nonpaired t-test were used to examine the association between smoking relapse and age, gender, age at smoking initiation, cigarettes smoked per day, previous abstinence, cohabiter, cohabitation with smokers, smokers at workplace or familiar places, having present diseases, strength of desire to smoke at 12 weeks, self-efficacy at 12 weeks, and CES-D score at 12 weeks. Subsequently, logbinomial regression analysis was used to examine factors associated with smoking relapse at 1 year. Finally, chi-squared test was used to examine the association between success of smoking cessation and smoking cessation medicine, and Fisher's exact test was used to examine the association between smoking relapse and smoking cessation medicine. All statistical analyses were performed using IBM SPSS Statistics 25.0. Values with $\mathrm{p}<0.05$ (two-tailed) were statistically significant.

\section{RESULTS}

\section{Participant flow}

A total of 153 participants who were screened for

\section{Figure 1. Flow of participants through study}

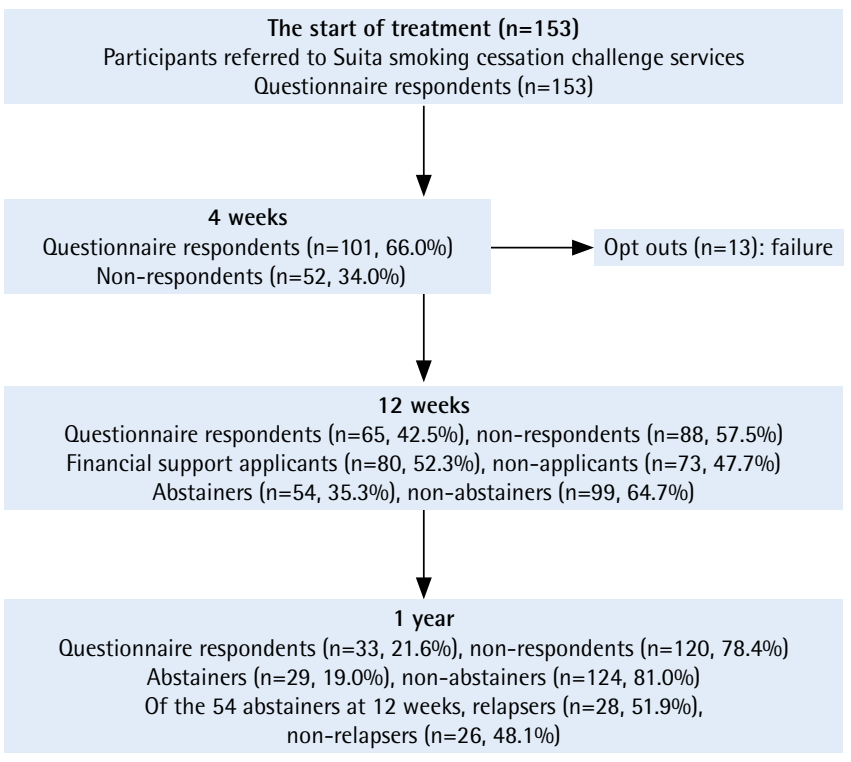

eligibility were referred to Suita smoking cessation challenge services from May 2017 to September 2018. At the start of treatment, all 153 participants answered the first questionnaire. At 4 weeks, 101 participants (66.0\%) answered the second questionnaire. At 12 weeks, 13 participants opted out during the period of treatment, and 140 participants $(91.5 \%)$ completed the 12 -week treatment. At 12 weeks, 65 participants $(42.5 \%)$ answered the third questionnaire, 54 participants $(35.3 \%)$ were confirmed as abstainers, and 80 participants $(52.3 \%)$ applied for financial support. At 1 year, 33 participants (21.6\%) answered the third questionnaire, 29 participants $(19.0 \%)$ were confirmed as abstainers, and of the 54 abstainers at 12 weeks, 28 abstainers (52.3\%) were confirmed as relapsers (Figure 1).

\section{Characteristics of the participants}

For the 153 participants, the mean age was 53.69 years $(\mathrm{SD}=13.056)$. Over $70 \%$ of the participants were male. The mean age at smoking initiation was 20.59 years $(\mathrm{SD}=3.882)$, and nearly $80 \%$ of the participants started smoking at 20 years of age or older. The mean number of cigarettes smoked per day was 20.57 ( $\mathrm{SD}=8.108)$, and over $60 \%$ of the participants smoked 11-20 cigarettes per day. Nearly $40 \%$ of the participants had present diseases, and over $60 \%$ had experienced previous abstinence. Over $80 \%$ of the participants were living with family, and nearly $15 \%$ were living with smokers. About $70 \%$ of participants had moderate $(32.7 \%)$ and strong (35.9\%) desire to smoke at the start of treatment. The mean value of self-efficacy at the start of treatment was $61.29(\mathrm{SD}=8.108)$, and over a half of participants had low self-efficacy to quit smoking $(\leq 60 \%)$. The mean CES-D score was 9.84 ( $\mathrm{SD}=8.284)$, and $22.9 \%$ of participants were diagnosed as being in a mood disorder group ( $\geq 16)$ (Table 1).

\section{Factors associated with success of smoking cessation at 12 weeks}

There were no factors statistically significantly associated with success of smoking cessation at 12 weeks $(\mathrm{p}<0.05)$. In the log-binomial regression analysis, male (OR=1.45, 95\% CI: 0.67-3.14), 21-30 $(\mathrm{OR}=0.44,95 \%$ CI: $0.12-1.69)$ and $>30(\mathrm{OR}=0.80$, 95\% CI: 0.16-4.08) cigarettes smoked per day, having present diseases $(\mathrm{OR}=1.58,95 \%$ CI: $0.80-3.10)$, 
Table 1. Characteristics of the participants in Suita city smoking cessation challenge services $(n=153)$

\begin{tabular}{|c|c|c|c|c|}
\hline & n & $\%$ & Vean & SI) \\
\hline Age (years) & & & 53.69 & 13.06 \\
\hline \multicolumn{5}{|l|}{ Gender } \\
\hline Male & 112 & 73.2 & & \\
\hline Female & 41 & 26.8 & & \\
\hline Age at smoking initiation (years) & & & 20.59 & 3.88 \\
\hline$<20$ & 33 & 21.6 & & \\
\hline$\geq 20$ & 120 & 78.4 & & \\
\hline Cigarettes smoked per day & & & 20.57 & 8.11 \\
\hline$\leq 10$ & 20 & 13.1 & & \\
\hline $11-20$ & 97 & 63.4 & & \\
\hline $21-30$ & 26 & 17.0 & & \\
\hline$>30$ & 10 & 6.5 & & \\
\hline \multicolumn{5}{|l|}{ Smoking cessation medicine } \\
\hline Not used & 73 & 47.7 & & \\
\hline Varenicline & 70 & 45.8 & & \\
\hline Nicotine patch & 9 & 5.9 & & \\
\hline Nicotine patch $\rightarrow$ Varenicline & 1 & 0.7 & & \\
\hline \multicolumn{5}{|l|}{ Having present diseases } \\
\hline Absence & 93 & 60.8 & & \\
\hline Presence & 60 & 39.2 & & \\
\hline \multicolumn{5}{|l|}{ Previous abstinence } \\
\hline Not experienced & 54 & 35.3 & & \\
\hline Experienced & 99 & 64.7 & & \\
\hline \multicolumn{5}{|l|}{ Cohabiter (missing value: 2) } \\
\hline Living alone & 22 & 14.4 & & \\
\hline Living with family & 129 & 84.3 & & \\
\hline \multicolumn{5}{|l|}{$\begin{array}{l}\text { Cohabitation with smokers } \\
\text { (missing value: } 2 \text { ) }\end{array}$} \\
\hline Absence & 126 & 82.4 & & \\
\hline Presence & 25 & 16.3 & & \\
\hline \multicolumn{5}{|l|}{$\begin{array}{l}\text { Smokers at workplace or } \\
\text { familiar places }\end{array}$} \\
\hline Absence & 26 & 17.0 & & \\
\hline Presence & 127 & 83.0 & & \\
\hline \multicolumn{5}{|l|}{$\begin{array}{l}\text { Strength of desire to smoke at } \\
\text { the start of treatment }\end{array}$} \\
\hline None & 3 & 2.0 & & \\
\hline Slight & 45 & 29.4 & & \\
\hline Moderate & 50 & 32.7 & & \\
\hline Strong & 55 & 35.9 & & \\
\hline $\begin{array}{l}\text { Self-efficacy at the start of } \\
\text { treatment in } \%\end{array}$ & & & 61.29 & 26.53 \\
\hline$\leq 60$ & 81 & 53.0 & & \\
\hline$>60$ and $\leq 80$ & 36 & 23.5 & & \\
\hline$>80$ and $\leq 100$ & 36 & 23.5 & & \\
\hline $\begin{array}{l}\text { CES-D score at the start of } \\
\text { treatment (missing value: } 2 \text { ) }\end{array}$ & & & 9.84 & 8.28 \\
\hline$<16$ & 116 & 75.8 & & \\
\hline$\geq 16$ & 35 & 22.9 & & \\
\hline
\end{tabular}

having previous abstinence ( $\mathrm{OR}=0.61,95 \% \mathrm{CI}: 0.31-$ 1.22 ), living with family ( $\mathrm{OR}=2.02,95 \%$ CI: $0.70-$ $5.81)$, cohabitation with smokers $(\mathrm{OR}=0.85,95 \% \mathrm{CI}$ : $0.34-2.12)$, slight ( $\mathrm{OR}=0.33,95 \%$ CI: $0.03-3.95)$, moderate $(\mathrm{OR}=0.19,95 \% \mathrm{CI}: 0.02-2.32)$ and strong $(\mathrm{OR}=0.29,95 \%$ CI: $0.02-3.35)$ desire to smoke at the start of treatment, $>60$ and $\leq 80 \%(\mathrm{OR}=0.51,95 \%$ CI: $0.20-1.27)$ and $>80$ and $\leq 100 \%(\mathrm{OR}=1.60,95 \%$ CI: 0.72-3.56) self-efficacy at the start of treatment, and then moderate $(\mathrm{OR}=0.60,95 \% \mathrm{CI}: 0.15-2.45)$ and strong ( $\mathrm{OR}=0.12,95 \% \mathrm{CI}$ : $0.01-1.32)$ desire to smoke at 4 weeks, $>60$ and $\leq 80 \%(\mathrm{OR}=1.62,95 \% \mathrm{CI}$ : $0.50-5.20)$ and $>80$ and $\leq 100 \%(\mathrm{OR}=2.36,95 \%$ CI: $0.85-6.55$ ) self-efficacy at 4 weeks showed statistically significant odds ratio for success of smoking cessation (Table 2).

\section{Factor associated with relapse at 1 year}

There were no factors statistically significantly associated with smoking relapse at 12 weeks $(\mathrm{p}<0.05)$. In the log-binomial regression analysis, male $(\mathrm{OR}=1.70,95 \%$ CI: $0.46-6.21), \geq 20$ years of age at smoking initiation ( $\mathrm{OR}=0.71,95 \%$ CI: $0.20-2.61$ ), 11-20 cigarettes $(\mathrm{OR}=0.64,95 \% \mathrm{CI}: 0.13-3.26)$ and 21-30 cigarettes smoked per day $(\mathrm{OR}=3.00,95 \% \mathrm{CI}$ : $0.21-42.62)$, having previous abstinence $(\mathrm{OR}=2.46$, 95\% CI: 0.82-7.45), living with family ( $\mathrm{OR}=0.20,95 \%$ CI: $0.02-2.11)$, cohabitation with smokers $(\mathrm{OR}=1.74$, 95\% CI: 0.37-8.18), moderate (OR=0.67, 95\% CI: $0.11-3.93)$ desire to smoke at 12 weeks, $>60$ and $\leq 80 \%(\mathrm{OR}=0.25,95 \% \mathrm{CI}: 0.02-2.95)$ and $>80$ and $\leq 100 \%$ (OR $=0.22,95 \%$ CI: $0.02-2.20)$ self-efficacy at 12 weeks and $\geq 16$ CES-D score at 12 weeks showed statistically significant odds ratio for smoking relapse (Table 3).

\section{Smoking cessation medicine associated with smoking cessation and relapse}

The association between smoking cessation medicine and smoking cessation was not statistically significant $(p=0.43)$, while the rate of abstainers using varenicline $(68.60 \%)$ was higher than abstainers using nicotine patch $(55.60 \%)$ (Table 4$)$. The association between smoking cessation medicine and relapse was statistically significant $(\mathrm{p}<0.05)$, and the rate of relapsers using nicotine patch was $100 \%$, significantly higher than relapsers using varenicline (45.80\%) (Table 5). 
Table 2. Factors associated with success of smoking cessation at 12 weeks in the Japanese smoking cessation treatment program

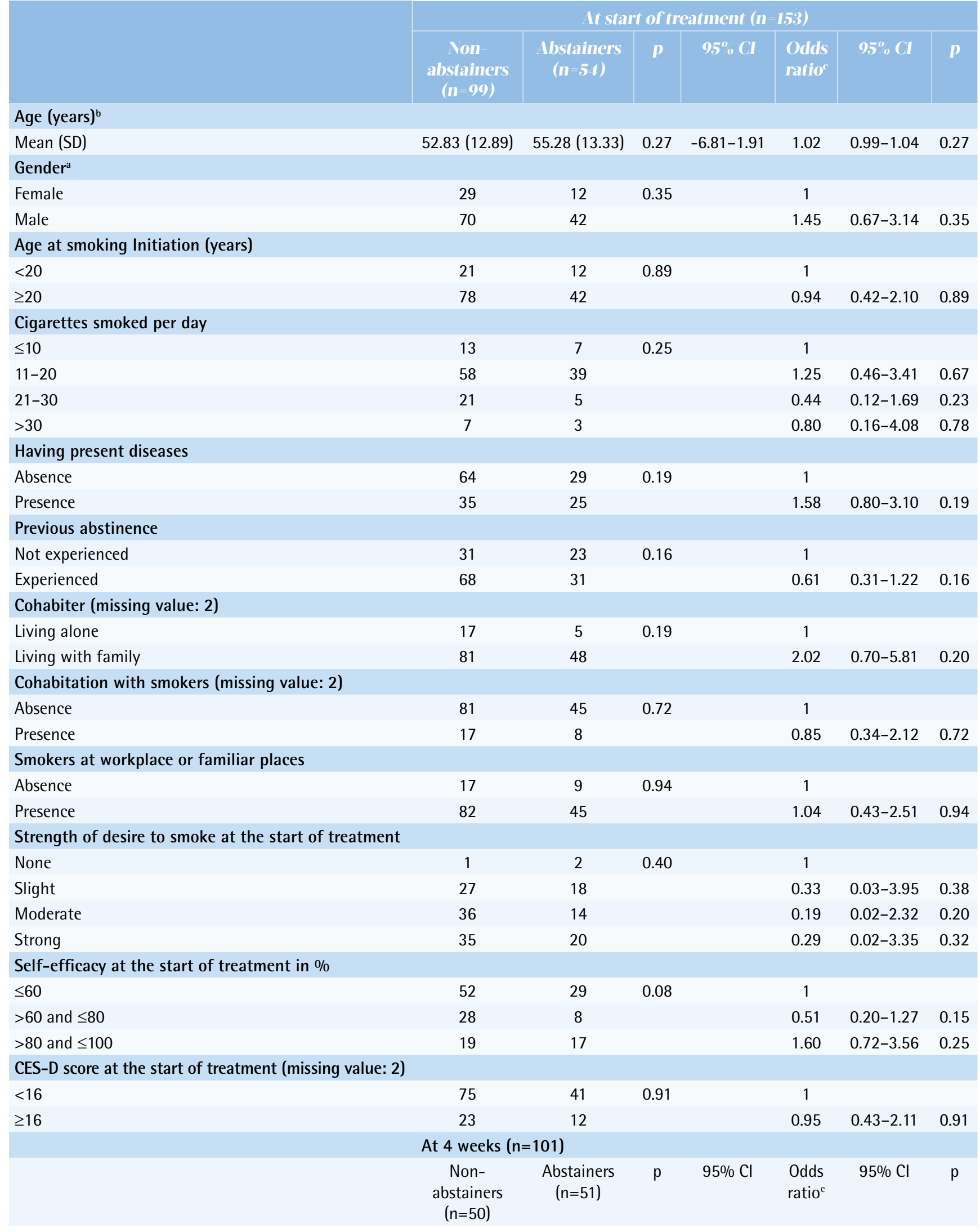


Table 2. Continue

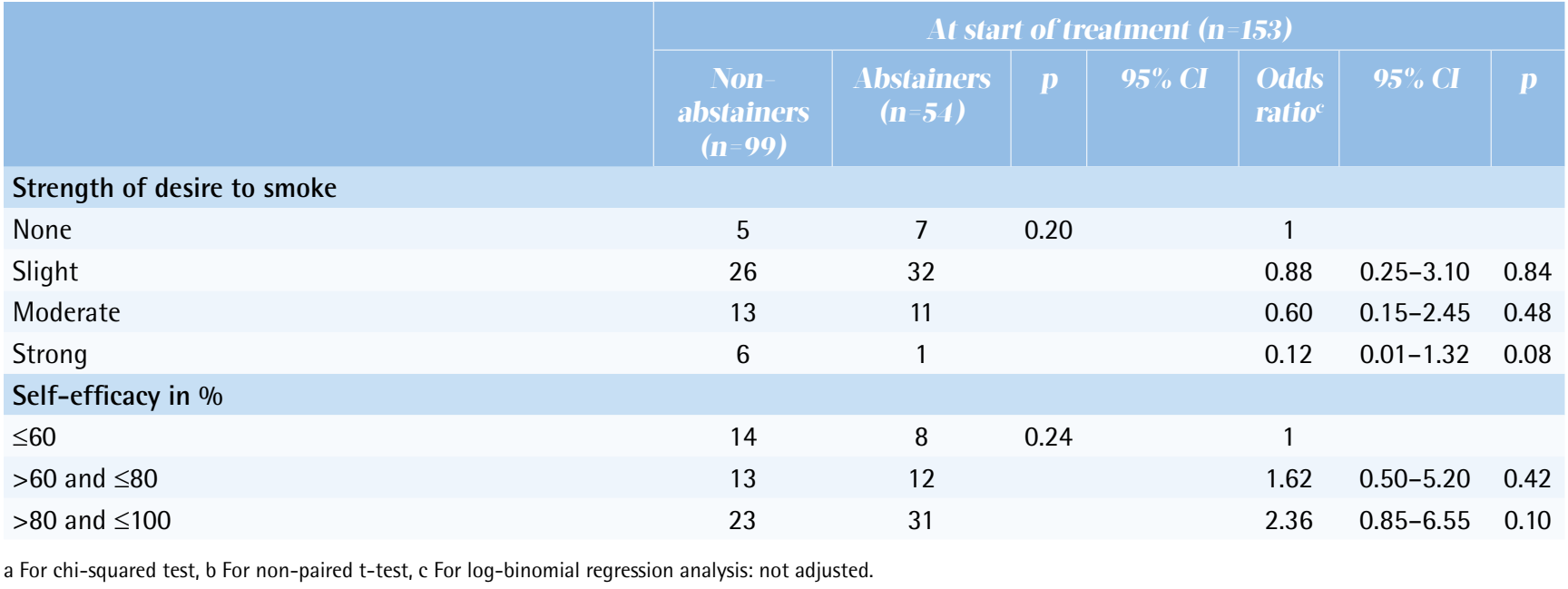

Table 3. Factors associated with smoking relapse at 1 year in the Japanese smoking cessation treatment program

\begin{tabular}{|c|c|c|c|c|c|c|c|}
\hline & \multicolumn{7}{|c|}{ At start of treatment $(n-51)$} \\
\hline & $\begin{array}{l}\text { Non } \\
\text { relapsers } \\
(\text { (n-26) }\end{array}$ & $\begin{array}{c}\text { Relapsers } \\
\left(\begin{array}{l}(n-28)\end{array}\right.\end{array}$ & $p$ & $95^{\circ} \circ \mathrm{CI}$ & $\begin{array}{l}\text { Odds } \\
\text { ratioc }\end{array}$ & $95 \% \mathrm{CI}$ & $p$ \\
\hline \multicolumn{8}{|l|}{ Age (years) ${ }^{b}$} \\
\hline Mean (SD) & $55.27(13.62)$ & $55.29(13.31)$ & 1.00 & $-7.37-7.34$ & 1.00 & $0.96-1.04$ & 1.00 \\
\hline \multicolumn{8}{|l|}{ Gender $^{\mathrm{a}}$} \\
\hline Female & 7 & 5 & 0.42 & & 1 & & \\
\hline Male & 19 & 23 & & & 1.70 & $0.46-6.21$ & 0.43 \\
\hline \multicolumn{8}{|c|}{ Age at smoking Initiation (years) } \\
\hline$<20$ & 5 & 7 & 0.61 & & 1 & & \\
\hline$\geq 20$ & 21 & 21 & & & 0.71 & $0.20-2.61$ & 0.61 \\
\hline \multicolumn{8}{|c|}{ Cigarettes smoked per day } \\
\hline$\leq 10$ & 3 & 4 & 0.49 & & 1 & & \\
\hline $11-20$ & 21 & 18 & & & 0.64 & $0.13-3.26$ & 0.59 \\
\hline $21-30$ & 1 & 4 & & & 3.00 & $0.21-42.62$ & 0.42 \\
\hline$>30$ & 1 & 2 & & & 1.50 & $0.09-25.39$ & 0.78 \\
\hline \multicolumn{8}{|c|}{ Having present diseases } \\
\hline Absence & 15 & 14 & 0.57 & & 1 & & \\
\hline Presence & 11 & 14 & & & 1.36 & $0.47-3.99$ & 0.57 \\
\hline \multicolumn{8}{|l|}{ Previous abstinence } \\
\hline Not experienced & 14 & 9 & 0.11 & & 1 & & \\
\hline Experienced & 12 & 19 & & & 2.46 & $0.82-7.45$ & 0.11 \\
\hline \multicolumn{8}{|c|}{ Cohabiter (missing value: 1 ) } \\
\hline Living alone & 1 & 4 & 0.17 & & 1 & & \\
\hline Living with family & 25 & 23 & & & 0.20 & $0.02-2.11$ & 0.20 \\
\hline \multicolumn{8}{|c|}{ Cohabitation with smokers (missing value: 1 ) } \\
\hline Absence & 4 & 5 & 0.81 & & 1 & & \\
\hline Presence & 22 & 23 & & & 1.74 & $0.37-8.18$ & 0.48 \\
\hline \multicolumn{8}{|c|}{ Smokers at workplace or familiar places } \\
\hline Absence & 17 & 9 & 0.94 & & 1 & & \\
\hline Presence & 82 & 45 & & & 0.84 & $0.20-3.53$ & 0.81 \\
\hline
\end{tabular}


Table 3. Continue

\begin{tabular}{|c|c|c|c|c|c|c|c|}
\hline & \multicolumn{7}{|c|}{ Mt start of treatment (n-51) } \\
\hline & $\begin{array}{l}\text { Yon } \\
\text { relapsers } \\
(\text { n- 26) }\end{array}$ & $\begin{array}{c}\text { Relapsers } \\
(\text { (n-28) }\end{array}$ & p & $95 \%$ CI & $\begin{array}{l}\text { Odds } \\
\text { ratioc }\end{array}$ & $95^{\circ} \circ \mathrm{CI}$ & $p$ \\
\hline \multicolumn{8}{|c|}{ Strength of desire to smoke } \\
\hline None & 1 & 1 & 0.89 & & 1 & & \\
\hline Slight & 8 & 10 & & & 1.25 & $0.07-23.26$ & 0.88 \\
\hline Moderate & 6 & 8 & & & 1.33 & $0.07-25.91$ & 0.85 \\
\hline Strong & 11 & 9 & & & 0.82 & $0.05-15.00$ & 0.89 \\
\hline \multicolumn{8}{|c|}{ Self-efficacy in $\%$} \\
\hline$\leq 60$ & 14 & 15 & 0.61 & & 1 & & \\
\hline$>60$ and $\leq 80$ & 5 & 3 & & & 0.56 & $0.11-2.79$ & 0.48 \\
\hline$>80$ and $\leq 100$ & 7 & 10 & & & 1.33 & $0.40-4.47$ & 0.64 \\
\hline \multicolumn{8}{|c|}{ CES-D score (missing value: 2 ) } \\
\hline$<16$ & 19 & 22 & 0.47 & & 1 & & \\
\hline$\geq 16$ & 7 & 5 & & & 0.62 & $0.17-2.27$ & 0.47 \\
\hline \multicolumn{8}{|c|}{ At 4 weeks $(n=51)$} \\
\hline & $\begin{array}{c}\text { Non-relapsers } \\
\quad(n=24)\end{array}$ & $\begin{array}{l}\text { Relapsers } \\
(n=27)\end{array}$ & $\mathrm{p}$ & $95 \% \mathrm{Cl}$ & $\begin{array}{l}\text { Odds } \\
\text { ratio }^{c}\end{array}$ & $95 \% \mathrm{Cl}$ & $\mathrm{p}$ \\
\hline \multicolumn{8}{|c|}{ Strength of desire to smoke } \\
\hline None & 3 & 4 & 0.51 & & 1 & & \\
\hline Slight & 14 & 18 & & & 0.96 & $0.19-5.03$ & 0.97 \\
\hline Moderate & 7 & 4 & & & 0.43 & $0.06-2.97$ & 0.39 \\
\hline Strong & 0 & 1 & & & - & - & - \\
\hline \multicolumn{8}{|c|}{ Self-efficacy in $\%$} \\
\hline$\leq 60$ & 2 & 6 & 0.40 & & 1 & & \\
\hline$>60$ and $\leq 80$ & 6 & 6 & & & 0.33 & $0.05-2.37$ & 0.27 \\
\hline$>80$ and $\leq 100$ & 16 & 15 & & & 0.31 & $0.05-1.80$ & 0.19 \\
\hline \multicolumn{8}{|c|}{ At 12 weeks $(n=54)$} \\
\hline & $\begin{array}{c}\text { Non-relapsers } \\
\quad(n=26)\end{array}$ & $\begin{array}{c}\text { Relapsers } \\
(n=28)\end{array}$ & $\mathrm{p}$ & $95 \% \mathrm{Cl}$ & $\begin{array}{l}\text { Odds } \\
\text { ratio }^{c}\end{array}$ & $95 \% \mathrm{Cl}$ & $\mathrm{p}$ \\
\hline \multicolumn{8}{|c|}{ Strength of desire to smoke } \\
\hline None & 8 & 9 & 0.88 & & 1 & & \\
\hline Slight & 14 & 16 & & & 1.02 & $0.31-3.35$ & 0.98 \\
\hline Moderate & 4 & 3 & & & 0.67 & $0.11-3.93$ & 0.65 \\
\hline Strong & 0 & 0 & & & - & - & - \\
\hline \multicolumn{8}{|c|}{ Self-efficacy in $\%$} \\
\hline$\leq 60$ & 1 & 4 & 0.39 & & 1 & & \\
\hline$>60$ and $\leq 80$ & 6 & 6 & & & 0.25 & $0.02-2.95$ & 0.27 \\
\hline$>80$ and $\leq 100$ & 19 & 17 & & & 0.22 & $0.02-2.20$ & 0.20 \\
\hline \multicolumn{8}{|c|}{ CES-D score (missing value: 1 ) } \\
\hline$<16$ & 23 & 24 & 0.47 & & 1 & & \\
\hline$\geq 16$ & 2 & 4 & & & 1.92 & $0.32-11.49$ & 0.48 \\
\hline
\end{tabular}


Table 4. Medicine associated with success of smoking cessation at 12 weeks in the Japanese smoking cessation program

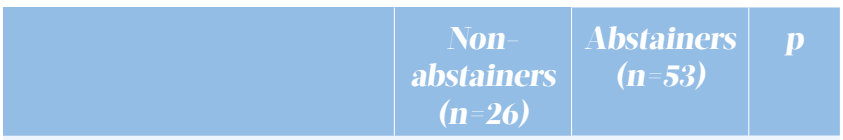

Smoking cessation medicine ${ }^{a}$

$\begin{array}{lrrr}\text { Varenicline } & 22(31.40 \%) & 48(68.60 \%) & 0.43 \\ \text { Nicotine patch } & 4(44.40 \%) & 5(55.60 \%) & \end{array}$

a For chi-squared test.

\section{DISCUSSION}

To the best of our knowledge, this is the first study to discuss the effects of providing financial support and factors associated with smoking cessation and relapse, based on financial support in Japan. From many studies ${ }^{10-17}$ it is obvious that the completion of the SCT program improved the success of smoking cessation, while the completion rate was very low $\left(68.0 \%^{10}, 50.0 \%^{11}, 36.3 \%^{18}, 56.9 \%^{19}, 32.4 \%^{20}\right)$. The completion rate of the SCT program in our study was $91.5 \%$, which is far higher than in these previous studies and in three previous surveys ${ }^{15-17}(30.0 \%$ in $2007,35.5 \%$ in 2009 , and $29.8 \%$ in 2017 ) reported by the Japanese Ministry of Health, Labor and Welfare. This comparison implies that providing financial support may improve the completion rate of smoking cessation programs, although this study is not a randomized controlled trial concerning the association between financial support and the completion of the SCT program.

Identification of factors associated with smoking cessation and relapse can help health care workers to improve the effectiveness of efforts to manage smoking behaviors. In regard to factors associated with smoking cessation at 12 weeks, there were no factors significantly associated with success in smoking cessation. However, we found that gender, cigarettes smoked per day, having present diseases, having previous abstinences, cohabiter, cohabitation with smokers, desire to smoke, and self-efficacy showed statistically significant odds ratio for success in smoking cessation. Similarly, our study also demonstrated that there were no factors significantly associated with smoking relapse at 1 year. However, we found that gender, age at smoking initiation, cigarettes smoked per day, having previous
Table 5. Medicine associated with smoking relapse at 1 year in the Japanese smoking cessation program

\begin{tabular}{l|c|c|c} 
& $\begin{array}{c}\text { Von } \\
\text { relapsers } \\
(n-26)\end{array}$ & $\begin{array}{c}\text { Relapsers } \\
(n-27)\end{array}$ & P \\
$\begin{array}{l}\text { Smoking cessation medicine } \\
\text { Varenicline }\end{array}$ & $26(54.20 \%)$ & $22(45.80 \%)$ \\
Nicotine patch & $0(0.00 \%)$ & $5(100.00 \%)$
\end{tabular}$<0.05$

abstinences, cohabiter, cohabitation with smokers, desire to smoke, and self-efficacy CES-D score showed statistically significant odds ratio for smoking relapse. In addition, our study demonstrated that the rate of abstainers using varenicline was $68.60 \%$, which was higher than abstainers using nicotine patch $(55.60 \%)$ at 12 weeks, while at 1 year the relapse rate of participants using nicotine patch was $100.00 \%$, significantly higher than relapsers using varenicline $(45.80 \%)$.

In regard to gender associated with success in smoking cessation, our study demonstrated that males were more likely to quit smoking than females, and this result was consistent with previous studies ${ }^{21-29}$. This may be because females had more severe withdrawal symptoms, higher satisfaction levels for smoking, limited methods in releasing stress, more strongly anxious about weight gain due to quit smoking, more sales strategies targeting women and more smokers in the family compared to male smokers $^{21}$. In general, nicotine dependence was a significant factor that prevented smoking cessation. Our study found that patients smoking 21-30 and $>30$ cigarettes per day found it difficult to quit smoking. This result may imply that high nicotine dependence is negatively associated with success of smoking cessation.

In our study, we found that having present diseases was positively associated with success of smoking cessation and this was consistent with previous studies $^{12,29}$. This may be because smokers with present diseases, especially smoking-related diseases such as cardiovascular diseases, COPD, are more concerned about their health and more eager to quit smoking. However, previous studies ${ }^{14,18,23,29}$ demonstrated that having mental diseases was negatively associated with 
success of smoking cessation. This difference implies that smokers with different present diseases may have different smoking cessation behavior. In addition, we found that having previous abstinence, living alone and cohabitation with smokers were negatively associated with success of smoking cessation and this result is consistent with previous studies ${ }^{5,12,14,21}$.

In regard to the short-term effect ( 12 weeks) of varenicline treatment, previous studies demonstrated that the rate of abstainers was $43.5-84.5 \%^{5,11,19,23,25-}$ 29,30-32 while our study demonstrated that the rate of abstainers was $68.60 \%$. Furthermore, with regard to the long-term effect ( 1 year) of varenicline treatment, previous studies demonstrated that the success rate was $46.6-68.4 \%^{5,25,28}$ while our study demonstrated that the success rate (non-relapsers) was $54.20 \%$. In addition, a recent randomized clinical trial ${ }^{33}$ showed no significant differences in rates of smoking abstinence between these two treatments. However, our study demonstrated that varenicline appeared to be more effective than nicotine patch in Japan and this result

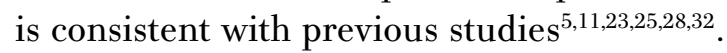

To date, studies have demonstrated that selfefficacy was positively associated with success of smoking cessation among smokers who received smoking cessation intervention ${ }^{6}$. In Japan, four previous studies ${ }^{5,6,14,23}$ also demonstrated that there was a positive association between self-efficacy and the success in smoking cessation, although selfefficacy was divided into several stages based on different scores. Furthermore, our study demonstrated that participants with self-efficacy scores $>80 \%$ at the first session and $>60 \%$ at the second session were more likely to attain abstinence than those with low self-efficacy scores, although there was not a statistically significant association $(p>0.05)$. These results suggest that maintaining participants' selfefficacy at a high level is able to enhance success of smoking cessation. In addition, a review of 21 studies examining predictors of more than 6 months cessation outcome found that self-efficacy predicted relapse among both self-quitters and treated smokers ${ }^{34}$. Our study also demonstrated that self-efficacy scores $>60 \%$ at 12 weeks were negatively associated with smoking relapse.

\section{Limitations}

There are several limitations in this study. First, the number of participants was only 153 and this may affect the efficiency of the results. Second, we only used self-report questionnaires to assess smoking status that was not biochemically verified. Third, $60.9 \%$ of participants had a present illness in our study. Therefore, these results may not be able to be applied to the general population. Fourth, the strength scale of desire to smoke was only used in Japan and the psychometric properties of this scale do not exist.

\section{CONCLUSIONS}

This is the first study in Japan to discuss the effects of providing financial support and factors associated with smoking cessation and relapse, based on financial support. Our results suggest that providing financial support may be able to improve the completion rate of the SCT program. Male, cigarettes smoked per day, having present diseases, having previous abstinence, living with family, cohabitation with smokers, desire to smoke at the start of treatment, self-efficacy at the start of treatment, desire to smoke at 4 weeks, selfefficacy at 4 weeks showed significant odds ratio for success of smoking cessation, although there was no statistically significant association ( $p>0.05)$. Similarly, male, age at smoking initiation, cigarettes smoked per day, having previous abstinence, living with family, cohabitation with smokers, desire to smoke at the start of treatment, self-efficacy at the start of treatment, desire to smoke at 12 weeks, self-efficacy at 12 weeks and CES-D score at 12 weeks showed significant odds ratio for smoking relapse, although there was no statistically significant association $(\mathrm{p}>0.05)$. In addition, our study suggests that varenicline is more effective than nicotine patch in the SCT program. Further research is expected to clarify the effect of providing financial support and the factors associated with smoking cessation and relapse in the SCT program based on financial support.

\section{REFERENCES}

1. World Health Organization. WHO report on the global tobacco epidemic, 2017. Geneva, Switzerland: World Health Organization; 2017. http://apps.who.int/iris/ bitstream/10665/255874/1/9789241512824-eng. pdf?ua=1\&ua=1. Accessed April 16, 2019.

2. Li M, Tada A, Kiya M, Okamoto R. The status and future directions of comprehensive tobacco control policies for the 2020 Tokyo Olympic Games: A review. Tob Induc Dis. 2019;17(April). doi:10.18332/tid/105453 
3. Ikeda $\mathrm{N}$, Inoue $\mathrm{M}$, Iso $\mathrm{H}$, et al. Adult mortality attributable to preventable risk factors for non-communicable diseases and injuries in Japan: a comparative risk assessment. PLoS Med. 2012;9(1):e1001160. doi:10.1371/journal.pmed.1001160

4. The Japanese Circulation Society, The Japan Lung Cancer Society, Japanese Cancer Association, The Japanese Respiratory Society. The Japanese smoking cessation treatment guideline for smoking cessation, 6th edition (In Japanese). http://www.j-circ.or.jp/kinen/ anti_smoke_std/pdf/anti_smoke_std_rev6.pdf. Published April 1, 2014. Accessed March 6, 2019.

5. Taniguchi C, Tanaka H, Saka H, et al. Cognitive, behavioural and psychosocial factors associated with successful and maintained quit smoking status among patients who received smoking cessation intervention with nurses' counselling. J Adv Nurs. 2017;73(7):16811695. doi:10.1111/jan.13258

6. Taniguchi C, Tanaka H, Saka H, et al. Changes in selfefficacy associated with success in quitting smoking in participants in Japanese smoking cessation therapy. Int J Nurs Pract. 2018;24(4):e12647. doi:10.1111/ijn.12647

7. Taniguchi C, Tanaka H. Counseling techniques for smoking cessation treatment (In Japanese). Science of Nursing, Japan. 2013.

8. Spek V, Lemmens F, Chatrou M, van Kempen S, Pouwer F, Pop V. Development of a smoking abstinence selfefficacy questionnaire. Int J Behav Med. 2013;20(3):444449. doi:10.1007/s12529-012-9229-2

9. Gwaltney CJ, Metrik J, Kahler CW, Shiffman S. Selfefficacy and smoking cessation: a meta-analysis. Psychol Addict Behav. 2009;23(1):56-66. doi:10.1037/a0013529

10. Tanaka M, Muta K, Iwatubo H. High Success Rate in Smoking Cessation Due to Cooperative Team Intervention (In Japanese). Official Journal of Japan Society of Ningen Dock. 2010;25(1):100-104. doi:10.11320/ningendock.25.100

11. Imamoto C, Suzuki K, Takahashi E, Takahashi C. Comparison between varenicline and nicotine patch in terms of smoking cessation, and effect of support by experienced nurses (In Japanese). Japanese Journal of Tobacco Control. 2010;5(1):3-9.

12. Yasuda M, Suzuki A, Takahashi A, et al. Analysis of factors associated with successful smoking cessation and conditions abstinence after smoking cessation therapy at our clinic (In Japanese). Health Evaluation and Promotion. 2015;42(3):385-391. doi:10.7143/jhep.42.385

13. Itakura Y, Saito E, Muramatsu H. Relationships between self-efficacy and continuation of smoking cessation among outpatients visiting a clinic for smoking cessation (In Japanese). Japanese Journal of Tobacco Control. 2016;11(2):22-30. doi:10.14950/jstc.11.22

14. Sugiyama M. Analysis of factors associated with varenicline therapeutic efficacy at three different hospitals (In Japanese). Japanese Journal of Tobacco Control.
2018;13(4):64-70. doi:10.14950/jstc.13.64

15. Central Social Insurance Medical Council, Japanese Ministry of Health, Labor and Welfare. Special investigation (2009 investigation) on medical treatment fee revision results inspection: the survey report on the rate of smoking cessation in medical institutions with nicotine dependence management fee calculation (In Japanese). https://www.mhlw.go.jp/shingi/2010/06/dl/ s0602-3i.pdf. Published June 2, 2010. Accessed March 26, 2019.

16. Central Social Insurance Medical Council, Japanese Ministry of Health, Labor and Welfare. Special investigation (2007 investigation) on medical treatment fee revision results inspection: the survey report on the rate of smoking cessation in medical institutions with nicotine dependence management fee calculation (In Japanese). https://www.mhlw.go.jp/shingi/2008/07/dl/ s0709-8k.pdf. Published July 9, 2008. Accessed March $26,2019$.

17. Central Social Insurance Medical Council, Japanese Ministry of Health, Labor and Welfare. Special investigation (2017 investigation) on medical treatment fee revision results inspection: the survey report on the rate of smoking cessation in medical institutions with nicotine dependence management fee calculation (In Japanese). https://www.mhlw.go.jp/file/05-Shingikai12404000-Hokenkyoku-Iryouka/0000192293.pdf. Published November 18, 2017. Accessed March 26, 2019.

18. Tomioka H, Wada T, Yamazoe M, Yoshizumi Y, Nishio C, Ishimoto $\mathrm{G}$. Ten-year experience of smoking cessation in a single center in Japan. Respir Investig. 2019;57(4):380387. doi:10.1016/j.resinv.2019.01.007

19. Iwaoka M, Shimamura H, Tsuji T, Kugiyama K. Twelve weeks of smoking cessation therapy with Varenicline increases the serum levels of apolipoprotein A-I only in the success group. J Cardiol. 2014;64(4):318-323. doi:10.1016/j.jjcc.2014.02.009

20. Ito A, Ito H, Miura $H$, Takahashi $Y$. Examination of factors influencing the short- and long-term success rate (1-year smoking cessation rate) of smoking cessation treatment with a nicotine patch (In Japanese). Smoking Cessation Science. 2008;2(2):17-22.

21. Uchida K. Smoking cessation treatment, analysis of smoking cessation rate, and the reason of lower smoking cessation rate in women compared with that in men (In Japanese). Annals of The Japanese Respiratory Society. 2007;45(9):673-678.

22. Shinoda C, Nagasawa C. Efficacy and safety of varenicline for smoking cessation treatment (In Japanese). The Journal of the Japan Society for Respiratory Care and Rehabilitation. 2011;21(2):123-127. doi:10.15032/jsrcr.21.2_123

23. Umene-Nakano W, Hayashi K, Yoshii C, et al. Outcome of smoking cessation therapy for nicotine dependents with psychiatric disorders (In Japanese). Japanese Journal of Tobacco Control. 2011;6(6):91-97. 
24. Satoh K, Seiji K, Mizoguchi K, Igarashi T, Matsui K. Smoking cessation rate and smoking persistence rate by gender in JR Sendai Hospital outpatient clinic (In Japanese). Japanese Journal of Tobacco Control. 2012;7(4):123-127.

25. Miyagi O, Toyosato T, Kobayashi S, Kawaguchi A. Epidemiological study for long lasting effect of smoking cessation treatment: follow up study during 3 months and a year (In Japanese). Journal of the Human Arts and Sciences. 2012;8(2):91-99. doi:10.11427/jhas.8.91

26. Okazaki S, Ueda K. Smoking cessation using varenicline: Relation between the abstinence rate and the age and gender (In Japanese). Annals of The Japanese Respiratory Society. 2013;2(4):327-332.

27. Yoshii C, Nishida C, Kawanami Y, et al. Evaluation of the 12-week treatment results by varenicline (Champix ()) (In Japanese). Japanese Journal of Tobacco Control. 2013;8(1):13-20.

28. Nobata S, Nishiwaki R, Shimokuri E, et al. Examination of Results of Smoking Cessation Treatment with Nicotine Patches or Varenicline in Ningen Dock or Health Check-up Subjects and Factors Influencing those Results (In Japanese). Official Journal of Japan Society of Ningen Dock. 2013;27(5):843-850. doi:10.11320/ningendock.27.843

29. Ishii M, Ohnishi T, Morisaki K, et al. Clinical response to varenicline as a smoking cessation aid (In Japanese). Japanese Journal of Tobacco Control. 2017;12(3):58-63. doi:10.14950/jstc. 12.58

30. Taniguchi C, Tanaka H, Itakura A, et al. Factors associated with 4-weeks quit rate before the end of smoking cessation therapy in Japan (In Japanese). Japanese Journal of Tobacco Control. 2011;6(3):34-39.

31. Iwaoka M, Tsuji T. Twelve Weeks of Successful Smoking Cessation Therapy with Varenicline Reduces Spirometric Lung Age. Intern Med. 2016;55:2387-2392. doi:10.2169/internalmedicine.55.6844

32. Shimadu S, Hamajima N, Okada Y, et al. Factors influencing sustainable efficacy of smoking cessation treatment with varenicline beyond nine months. Nagoya J Med Sci. 2016;78(2):205-213.

33. Baker TB, Piper ME, Stein JH, et al. Effects of nicotine patch vs varenicline vs combination nicotine replacement therapy on smoking cessation at 26 weeks: a randomized clinical trial. JAMIA. 2016;315(4):371-379. doi:10.1001/jama.2015.19284

34. Gwaltney CJ, Shiffman S, Balabanis MH, Paty JA. Dynamic self-efficacy and outcome expectancies: prediction of smoking lapse and relapse. J Abnorm Psychol. 2005;114(4):661-675. doi:10.1037/0021-843X.114.4.661
ACKNOWLEDGEMENTS

The authors gratefully acknowledge the staff at the Health Center of Suita City for their guidance and partnership. The authors also thank other members of the Public Health Nursing Laboratory for helpful comments and advice on this manuscript.

\section{CONFLICTS OF INTEREST}

The authors have completed and submitted the ICMJE Form for Disclosure of Potential Conflicts of Interest and none was reported.

\section{FUNDING}

There was no source of funding for this research.

PROVENANCE AND PEER REVIEW

Not commissioned; externally peer reviewed. 